\title{
EVALUATION OF CONCEPT LEARNING DEFICIENCIES ENCOUNTERED IN TEACHING SLOPE IN THE EMERGENCY DISTANCE EDUCATION PROCESS
}

\author{
Elif Ertem Akbaşi, \\ Kübra Alan \\ Van Yüzüncü Yıl University, \\ Faculty of Education, \\ Van, Turkey
}

\begin{abstract}
:
Due to the fact that the pandemic process did not occur in a predictable time frame, various difficulties have arisen in the field of education. This is also true in mathematics education, and concretization has been one of the biggest obstacles. This situation paved the way for concept learning errors that may occur in students. There are some basic problems encountered in teaching the subject of slope. In this study, the purpose was to evaluate the concept learning deficiencies encountered in teaching the subject of slope by using real life problems with the help of Geogebra. The study had an action research design based on a qualitative approach. The participants of the study were $138^{\text {th }}$ grade students attending a public school in Turkey. As the data collection tool, the activity named Bicycle-Slope, which was prepared by Kavak (2013) and which was available on the website of Geogebra, was used. In addition, 4 sub-questions were directed to the students. Moreover, the data were photographed with a camera, recorded with a voice recorder and analyzed descriptively. At the end of the study, when the responses of the students were observed, it was seen that there was a decrease in most of the concept learning errors that occurred.
\end{abstract}

Keywords: emergency distance education, Realistic Mathematics Education (RME), slope, Geogebra

\section{Introduction}

One of the most affected areas during the Covid 19 pandemic, which started in December 2019 and influenced the whole world after a certain period of time, has been the field of education (Bozkurt \& Sharma, 2020). In order to compensate for education, many institutions took action all over the world with emergency distance education applications (Bozkurt, 2020). The main goal in this process was to create an immediate

'Correspondence: email eertema@gmail.com 
solution to the disrupted education process (Sezgin, 2021). Distance education became a necessity rather than a method that can be applied in all countries in the world during the epidemic (Telli \& Altun, 2020). This was like a break time bell for students to take a break from face-to-face teaching, away from the classroom. This time, they were in front of the screens for educational purposes and tried to overcome the "home schooling" process successfully. Now, the house also took on duties such as school and workplace (Bakker \& Wagner, 2020). This process inevitably brought along some reactions in the students' interest in lessons. Sarıtaş and Barutçu (2020), in their study, investigated the students' readiness for online education. Within the framework of the results obtained, it was revealed that the students evaluated themselves negatively in terms of their control over the online learning process. In addition, not only students and instructors' lack of computer use skills but also health problems that may occur in long-term computer use (Kilit \& Güner, 2021) can be considered to be among the reasons that form the basis of the reactions that may occur.

In mathematics education, with the pandemic period, a transition has been made to the beginning of a period in which new alternatives will be examined. Many mathematics teachers supported schools with arrangements to cover distance mathematics education (Bakker \& Wagner, 2020). According to the findings obtained in a study conducted by Kilit and Güner (2021), the researchers determined the views of teachers about web-based learning in mathematics teaching. In their study, the teachers mentioned the advantageous features of the visual and audio materials presented in webbased learning, saying that they saved money and time. On the other hand, the teachers also stated that these materials had disadvantages because they could not contact students on one-on-one basis. While one-on-one contact with students and the use of materials increase the efficiency of concrete learning, it also allows preventing conceptual errors likely to arise (Kocaoğlu \& Yenilmez, 2010). In addition, immediate feedback and corrections will be a positive breakthrough in grounding the student's knowledge. It could be stated that similar conditions are required for geometry, which is one of the fields of mathematics that needs visual tools most.

Saying that the language of the universe is mathematics, Galileo further stated that the letters of this language are in geometrical forms. In this respect, geometry appears as an effort to make sense of existence rather than a gateway. Geometry, which allows human beings to make sense of their surroundings by carrying them into a free environment, also provides students with the opportunity to know more closely the world they live in (Gül, 2014). The slightest problem that may be encountered in this recognition phase may lead to some rigid thoughts such as lack of knowledge and "difficult lesson", which is hard for the student to return. For this reason, one of the best alternatives that can be used in geometry teaching could be to benefit from information technologies (Gürbüz, 2008). Use of information technologies makes it possible for students to have a concrete experience about the appearances that they cannot include in their mental processes as well as to appeal to more than one sense organ of the student. Students can access such experiences with the help of dynamic software (Topraklıkoğlu, 
2018). Dynamic mathematics software is one of the most important tools in terms of the opportunities they offer in examining geometric representations of mathematical concepts (Kabaca, Çontay \& İymen, 2011). It aims to examine these representations in Geogebra, which is a dynamic mathematics software (Hohenwarter \& Preiner, 2007). The fact that the algebra window and the graph window are side by side allows a change in the algebraic expression to be observed in the graph (Hohenwarter \& Hohenwarter, 2011). The teaching of the subject of slope similarly helps give meaning to the changes. The concept of slope, which can be defined as the ratio of the vertical change between any two points of a line to the horizontal change, is included in the algebra sub-learning area in the secondary school curriculum. This concept occurs in the $8^{\text {th }}$ grade curriculum as the outcomes of "Explains the slope of the line with its models." and "Relates the equation and graphs of the line with the slope."

\subsection{The Place of Slope in Mathematics Curriculum}

Since the concept of slope, which appears with the sub-learning area of algebra, can be defined as the ratio of a certain change, it would be appropriate to first examine how the concept of change is handled in the curriculum. Although the concept of change first appears in our minds as a concept belonging to objects, it is possible to include the quantitative changes such as length change as well as shape change here. When examined in this respect, we see that the conceptual ground first appears in the mathematics curriculum (for $1^{\text {st }} 4^{\text {th }}$ grades) together with the sub-learning area of Natural Numbers, which belongs to the learning area of Numbers and Operations. The concept of change here is mostly considered to be qualitative, on the basis of the patterns of shapes and numbers. When the curriculum (for $5^{\text {th }}-8^{\text {th }}$ grades) is examined, we now come across with the sub-learning area of Algebra where we can examine the changes in length or the quantitative changes. The sub-learning area of algebra is first included in the $6^{\text {th }}$ grade, and it is progressed through various associations again with emphasis on patterns. When the student passes to the $7^{\text {th }}$ grade, two sub-learning areas appear. These are:

1) Algebraic Expressions

2) Equality and Equation, respectively.

While algebraic expressions constitute the theoretical basis of the concept of change here, dependent and independent variables can become meaningful together with the quantitative changes with the student's passing to the sub-learning area of equality and equation (Uzun, 2018). This adventure, which has been going on from the very beginning and paving the way for making sense of the dependent and independent variable, is taken in a wider range with the sub-learning areas of Algebraic Expressions and Identities, Linear Equations and Inequalities when it comes to the $8^{\text {th }}$ grade. Making sense of the concept of slope is discussed in detail with the subject of linear equations (MNE, 2018). The process of giving meaning algebraically to the concept of slope can create question marks about the geometric construction process of this concept. In response to this, it could be stated that the concept of slope reappeared as a specific subject in the $11^{\text {th }}$ grade in a way to be included in the sub-learning area of Geometry. 
Here, a theoretical definition of slope will be made, and the gain given in this respect is as follows: "The slope angle and slope of a line is defined."

After the sub-learning area of Geometry, where the distance of a point from a line is also mentioned, the concept of average rate of change emerges in the learning area of Numbers and Operations. This gives us information that the theoretical basis of the concept of slope, which was created in the previous sub-learning area, has not yet been fully understood and will be realized with various combinations. In the $12^{\text {th }}$ grade, a relationship can be established between the definition of slope and the derivative calculation belonging to the learning area of numbers and operations because the derivative value is equal to the value of the slope of the function at a certain point (MNE, 2020). Thus, the theoretical and practical basis of change is completed, and the idea that the essence of the concept of slope is actually formed by the concept of change becomes meaningful. The concept of slope, which was grounded in the mathematics curriculum in Turkey in a period of 12 years, has also found its way in daily life. Although the idea that it has a quantitatively complex structure is dominant, it is estimated that students can give meaning to it more easily with detailed teaching techniques.

In this study, Geogebra was used in order to recognize the deficiencies predicted in the teaching of the subject of slope, which is a subject that challenges the visual memory and inevitably expands the cognition level of the students. Within the framework of the learning outcome of "Explains the slope of a line with models; relates linear equations and graphs to slope", which was found in the lesson unit of Linear Equations in the $8^{\text {th }}$ grade curriculum, the students were expected to solve a problem situation that they would encounter in daily life by transforming it into various questions. In the study, the activity prepared by Kavak (2013) named Cycling-Slope (https://www.geogebra.org/m/BQnDeXtw), which was available on the website of Geogebra, was used. Realistic Mathematics Education (RME) was used by making use of the problems that the students encountered in their daily lives. RME is a learning and teaching theory related to mathematics education, which was first introduced and developed by the Freudenthal Institute in the Netherlands in 1971 (Üzel, 2007). Freudenthal regarded learning mathematics as a process of making sense and commented that "mathematics, for the child, starts with making sense, and in order to do real mathematics, giving meaning must be taken as basis at every new stage" (Tomic \& Nelissen, 1998). In this respect, real-life problems were used in order to increase the children's levels of understanding. The purpose of the study was to make students aware of the estimated concept learning deficiencies regarding slope and then to evaluate these learning deficiencies. In line with this purpose, the research problem was related to the question of "How can the conceptual deficiencies of the students be evaluated during the teaching of slope in the distance education process?" 


\section{Method}

This section presents information about the research design, the study group, the data collection tool and the collection and analysis of the data.

\subsection{Research Design}

In this study, the purpose was to evaluate the students' awareness of their incomplete or wrong learning of the concept of slope by using realistic life problems in teaching the subject of slope and by using dynamic geometric software in the solution of these problems. The research method used in the study was the action research design, one of the qualitative research methods. In action research, the practitioner also functions as the person collecting the data (Yıldırım \& Şimşek, 2018). Action research is a type of research which is carried out by the practitioner on his/her own or together with a researcher and which includes systematic data collection and analysis to reveal the problems related to the application process or to understand and solve a problem that has already arisen (Yildırım \& Şimşek, 2018). In this study, the practitioner and the data collector researcher tried to solve, interpreted and evaluated the problems related to the process together with another researcher.

\subsection{Study Group}

The study group consisted of $138^{\text {th }}$ grade students attending a public secondary school located in Belen, a district of the province of Hatay in Turkey. The study group was determined using the maximum variety sampling in order to reflect the diversity of individuals who might have been a part of the problem at maximum level (Yildirim \& Şimşek, 2018). In this way, the probability of reflecting different perspectives was increased (Creswell, 2020).

\subsection{Validity and Reliability of the Study}

The validity and reliability tests in quantitative research are replaced by expressions such as credibility, confirmability of results, and dominance of the researcher in qualitative research (Krefting, 1991). In this respect, the questions to be used in the application phase of the study were examined by a mathematics instructor who was an expert in the field. In addition, the activity taken from geogebra.org and to be used in the study was sent for the expert's review along with the questions. Considering the corrections suggested by the expert, the activity was finalized, and the application was conducted. At the end of the application process, student feedback was given with direct quotations in order to ensure the validity and reliability of the study. The data obtained were recorded to ensure the confirmability of the study.

\subsection{Data Collection Tools and Collection of the Data}

In this study, an activity named Bicycle-Slope and prepared by Kavak (2013), which was taken from the website of Geogebra (https://www.geogebra.org/m/BQnDeXtw) and 
which was a life-related problem, was used in order to make students aware of their predicted incomplete or incorrect learning about the subject of slope and then to evaluate them. Along with this, 4 sub-questions were directed to the students. The questions were asked to the students in order, and the students were expected to solve them. The students were prevented from exchanging ideas with their friends at close distance in order to ensure the social distance due to the pandemic. After the students made their own solutions, a volunteering student came in front of the board and showed the solution step by step in the activity called Bicycle-Slope, which was opened on the interactive whiteboard. Photos of these processes were taken, and the processes were audiorecorded. Following this, the students were given time to compare their drawings and to notice if they had incomplete or wrong learning. When we came to the end of our question, they were asked to explain whether they would prefer this way or not expressing their reasons. In this part, the students freely expressed their opinions. After writing their ideas on the solution papers, these papers were photographed as well. Additional interviews were held with the students in order to give meaning to the operations they did in incomprehensible parts.

The questions directed to the students are given below:

You are planning to go on a long journey by your bike. You are planning a journey that will tire you less by calculating the slopes of the roads you can use by your bike, and the starting and ending coordinates of the linear roads you can use are given below. Draw the roads whose coordinates are given to you, and then indicate whether you would prefer them or not by stating the reasons.

1) Starting $=(-5,0)$

Ending $=(5,15)$

Would you prefer this road? Why?

2) Starting $=(-2,10)$

Ending $=(4,2)$

Would you prefer this road? Why?

3) Starting $=(-1,20)$

Ending $=(-1,40)$

Would you prefer this road? Why?

4) You have entered a road that you can't see the end of, and the coordinates of the road are

Starting $=(15,3)$

Ending $=(50,3)$

Would you prefer this road? Why? 


\subsection{Data Analysis}

The sound records and the papers where the students had solved the questions were carefully examined, grouped and analyzed descriptively in line with the questions directed in line with the research problem. The purpose of descriptive analysis is to present the findings to the reader in an organized and interpreted manner (Yildirım \& Şimşek, 2018). In addition, since direct quotations are included in the views of the individuals interviewed or observed in this type of analysis, the deficient learnings of the students were interpreted with the support of direct quotations. In this way, the causes of deficient learning were determined and evaluated. The names of the students used in the quotations were coded as "S1, S2, .., S13" within the framework of ethical rules. Moreover, the researcher was coded as "R" in the researcher-student dialogues presented in the findings.

\subsection{Limitations of the Study and the Precautions Taken}

Although Geogebra provides many conveniences for visualizations, situations such as directly obtaining the desired curve by writing the equation can be disadvantageous (Kaya \& Er, 2017; Aktümen, Horzum, Y1ld1z \& Ceylan, 2010; Kutlucaca \& Zengin, 2011). The reason for this is that the student cannot observe the movements of the curve. Since there might basically be such problems and others, first of all, the students were asked to draw the given lines themselves in the study. After the students drew, the line to be created in the activity in Geogebra was formed, and the movement of the bicycle was ensured. In this way, the student would be able to interpret, and it was possible for them to become aware of the problems they encountered in drawing the line.

\section{Findings}

In the introduction part, students were asked to draw the road with the coordinates of ($5,0)$ and $(5,15)$ in our problem in order to check their knowledge. Below are some of the students' drawings.

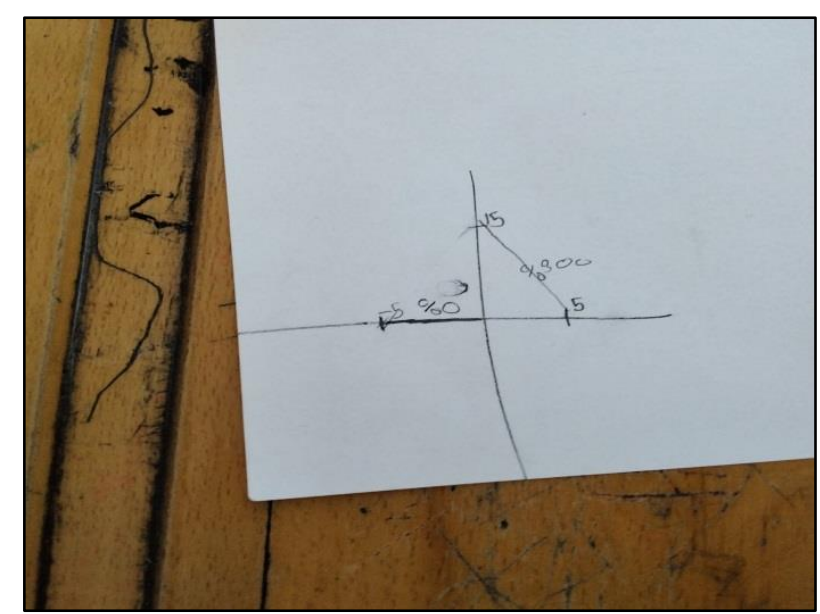

Figure 1: S3's drawing on the solution paper 
When the drawing was examined, it was seen that the student's understanding of the point $(5,15)$ as two different points like $(5,0)$ and $(0,15)$ and his/her drawing it correctly according to this show the existence of conceptual errors in the student. Part of the interview with the student is as follows:

R: Does this line you have drawn indicate the point $(5,15)$ ?

S3: Yes, it does because the intention was to cut the $x$-axis at point 5 and the $y$-axis at point 15 .

R: Do you think the points where the intention was to cut the $x$-axis and the y-axis were given, or do you think the points that would intersect the line to be drawn were given?

S3: Isn't that the line to be drawn?

R: How many lines did you draw?

S3: Two ... I think I made a mistake...

As it can be understood from the conversation, the student had a problem with the representation of the points in the coordinate system.

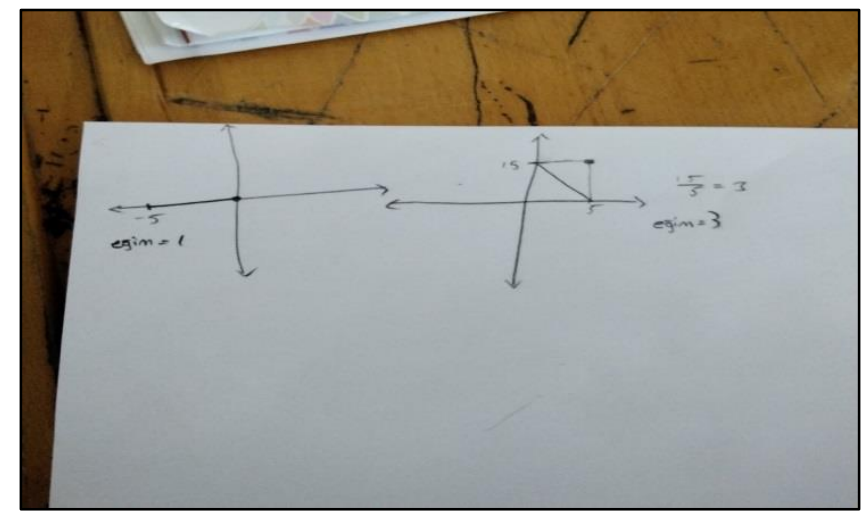

Figure 2: S7's drawing on the solution paper

Another student had the same misconception, but there was false information that the slope of the lines parallel to the $x$-axis would be 1 . In relation to this, the details of the interview with the student are as follows:

S7: Aren't these two, aren't there different ways like this?

$\mathrm{R}$ : Do you think you here drew the points given to you, or are the ones you have lines rather than points?

S7: These are the points. For example, you can see the points 5 and 15 here (showing on paper).

R: So, what you were required to have is the points 5 and 15 , or is it the point of $(5,15)$ ?

S7: We should have done a point drawing. I did it wrong.

R: How did you calculate the slope on the first graph you drew? 
S7: Slope is the ratio of the vertical distance to the horizontal distance. There is no vertical distance here, so the slope must be constant. Thus it's 1 .

$\mathrm{R}$ : Is it 1 when constant?

S7: So, it really shouldn't be. I mean there shouldn't be the slope. For that reason... $\mathrm{R}$ : Is it equal to 1 without the slope?

S7: No, it has to be 0 .

It was observed that the student had problems with the point representation and in adapting his/her knowledge of slope to practice.

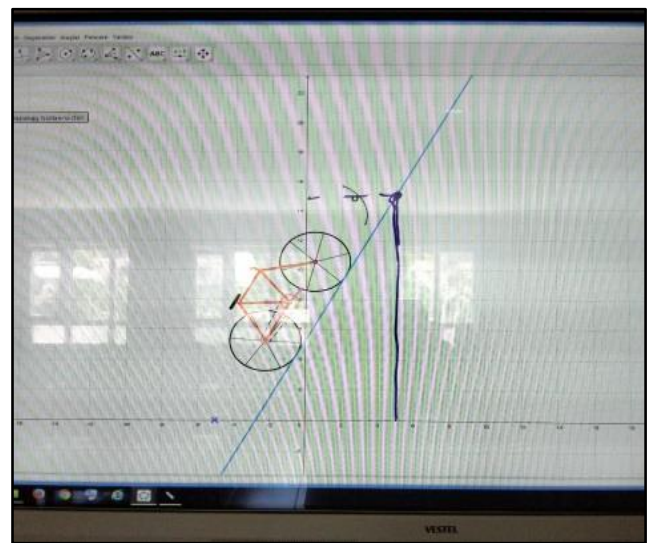

Figure 3: S7's solution on the Geogebra screen

Next, one of the students formed the line on the activity and provided the movement of the bicycle. In this way, the movement of the bicycle on the road was also observed. The students generally commented that this way could be preferred yet stated it could be tiring.

Table 1: General Evaluation of the first question

\begin{tabular}{|l|c|}
\hline Concept Deficiencies & Student Codes \\
\hline Those who had incomplete knowledge about point drawing & S3, S7, S12 \\
\hline Those who lacked theoretical and practical knowledge about slope & S2, S8 \\
\hline Those who lacked practice with slope & S1, S3, S7, S12 \\
\hline Those who had difficulties in transferring to the daily life & S1, S2, S3, S4, S5, S6, S7, S8, S12 \\
\hline
\end{tabular}

The conspicuous deficiencies and their frequencies following the first question can be seen in the table. The difficulty in making comments by associating with daily life is also obvious in the table. This phenomenon, which corresponds to approximately $69 \%$, also affects the students' interpretation of the connection between mathematics and daily life.

When the second question was being solved, it was observed that there was a noticeable improvement in the students. 


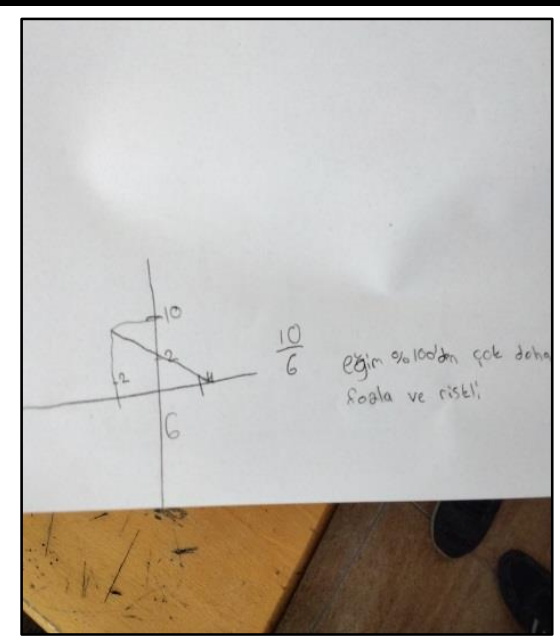

Figure 4: S11's drawing on the solution paper

When the visual is examined, it is seen that the student drew the point $(4,2)$ as two different points and calculated the value of the slope incorrectly. Part of the interview with the student is as follows:

R: ... So why did you show point $(4,2)$ this way?

S11: Because the question asked me to combine 4 and 2.

$\mathrm{R}$ : Then, do you think you found the place where 4 and 2 intersect here?

S11: Yes. 4 and 2 intersect on this line.

R: Can you show where 4 and 2 intersect on the line?

(The student paused for a while and then realized that he had shown it wrongly.)

R: How did you calculate the value of the slope?

S11: Teacher, the horizontal distance was actually 6, and the vertical distance was

10. But I miscalculated because I had drawn it wrong.

R: So, what can you say about its sign?

S11: It should have been negative as it was slanted to the left.

$\mathrm{R}$ : Why is it negative when slanted to the left?

S11: Well... actually, I don't know. It must be negative.

As can be understood from the solution of the second question, the students were not generally aware of why the sign of the slope changed, yet they did not feel the need to question it.

Table 2: General Evaluation of the second question

\begin{tabular}{|l|c|}
\hline Concept Deficiencies & Student Codes \\
\hline $\begin{array}{l}\text { Those who had incomplete knowledge about } \\
\text { point drawing }\end{array}$ & S7, S11, S12 \\
\hline $\begin{array}{l}\text { Those who had practical knowledge of the slope } \\
\text { sign. }\end{array}$ & S1, S2, S3, S4, S5, S6, S7, S8, S9, S10, S11, S12, S13 \\
\hline $\begin{array}{l}\text { Those who had theoretical knowledge about the } \\
\text { slope sign. }\end{array}$ & S9, S10 \\
\hline
\end{tabular}


Here, in the interviews with S9 and S10, the students were asked why the slope was negative. The answer given by $\mathrm{S} 9$ is as follows:

S9: ... The slope is negative because the numbers on the x-axis are increasing, while the numbers on the $y$-axis are decreasing. Therefore, the result will be negative.

S10 gave the same answer and showed it. At the same time, s/he gave an example from daily life and established the relationship of the subject with different subjects.

R: Why was the slope negative?

S10: There is an inverse relationship here.

$\mathrm{R}$ : What do you mean by inverse relationship?

S10: It's an inverse ratio.

R: Got it, you can go on.

S10: For example, as the number of employees increases, the time to do the work decreases. Here, too, as the numbers on the $\mathrm{x}$-axis increase, that is, as the distance traveled horizontally increases, the vertical path we take moves in the opposite direction. If we think like this, there is an inverse ratio here too. So, the slope must be negative ...

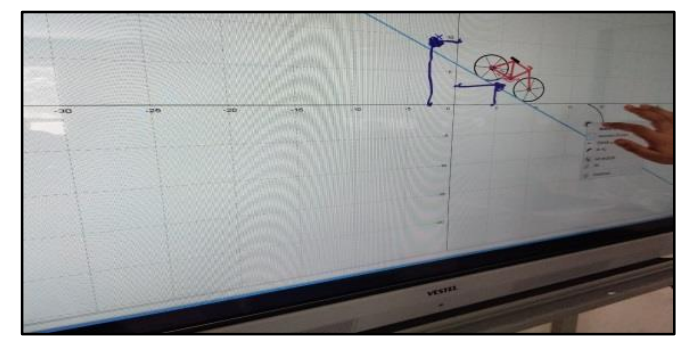

Figure 5: The solution made by S10 on the Geogebra screen

In the third question, the students were asked to analyze a line which they came across with and which often led to conceptual confusion.

The students generally used the concepts of no slope and slope $=0 \%$ together and claimed that the two meant the same.

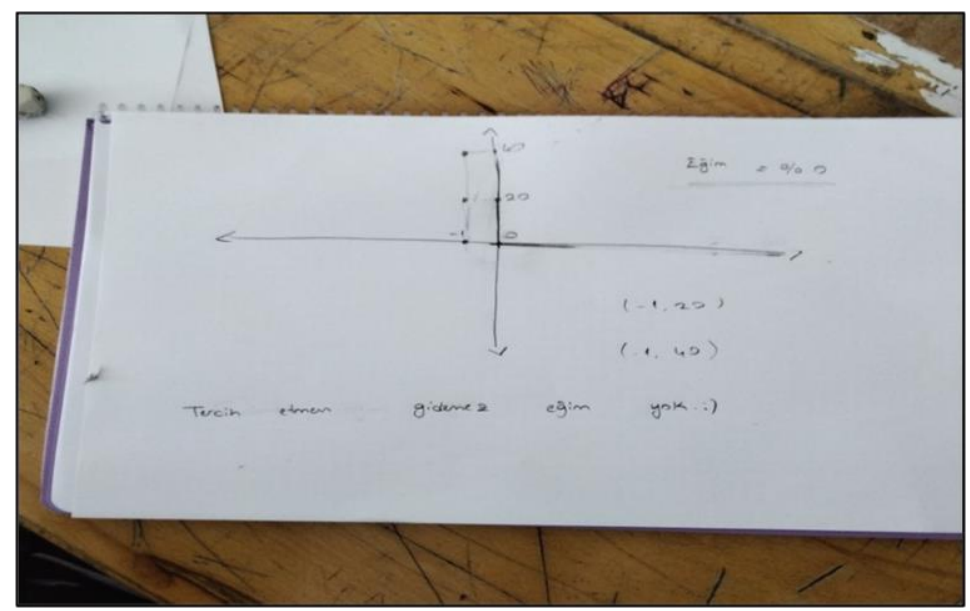

Figure 6: The drawing that S6 made on the solution paper 
The interview with S6 is as follows:

$\mathrm{R}:$... So, no slope, or is it $0 \%$ ?

S6: Aren't they both the same anyway?

$\mathrm{R}$ : Do you think it is the same?

S6: Yes, because absence also means being 0 , and 0 represents absence.

R: Why did you say no slope?

S6: Since its denominator is 0 .

$\mathrm{R}$ : Can you write $0 \%$ as a rational number?

S6: $\frac{0}{100}$

R: But its denominator isn't 0? Why no slope?

S6: Yes, I understand now. There should be no slope in this question because it does not move horizontally when the denominator is zero.

Table 3: General Evaluation of the third question

\begin{tabular}{|l|c|}
\hline Concept Deficiencies & Student Codes \\
\hline Slope $=\% 0$ and no slope error & S1, S2, S3, S5, S7, S8, S11, S12, S13 \\
\hline
\end{tabular}

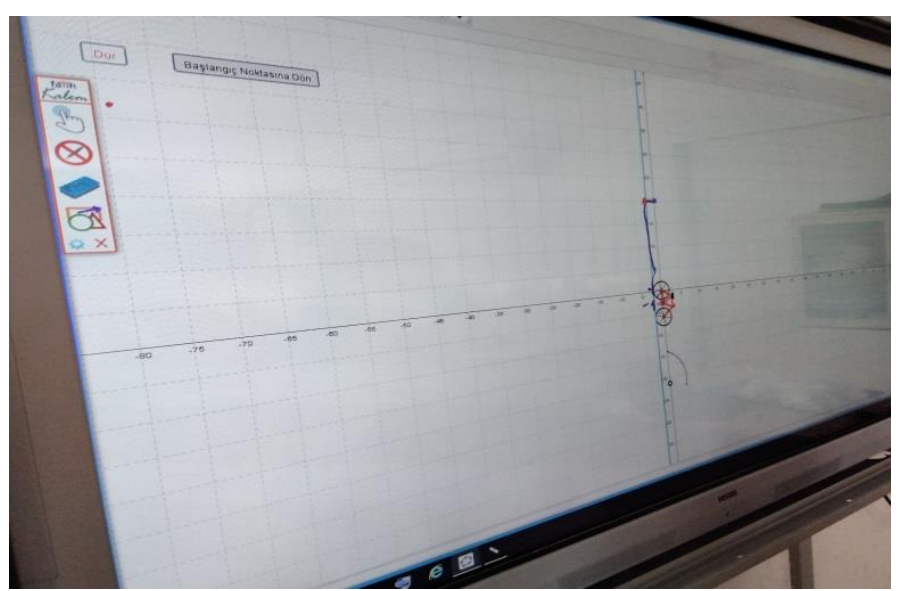

Figure 7: S1's solution on the Geogebra screen

The comment made by the students after seeing the activity was that they would not prefer this way. At the same time, there were comments like "How does a bike climb up a wall?" and "This is a dead end!"

The situations encountered in the fourth question are given below: 


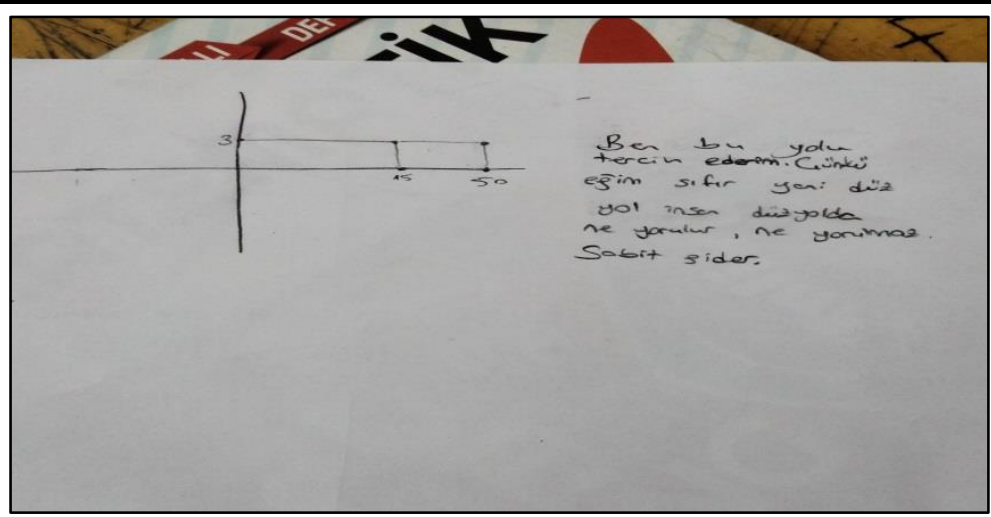

Figure 8: The drawing made by S5 on the solution paper

All of the students answered this question correctly after the third question. After seeing it in the activity, they commented that the straight road was always preferable.

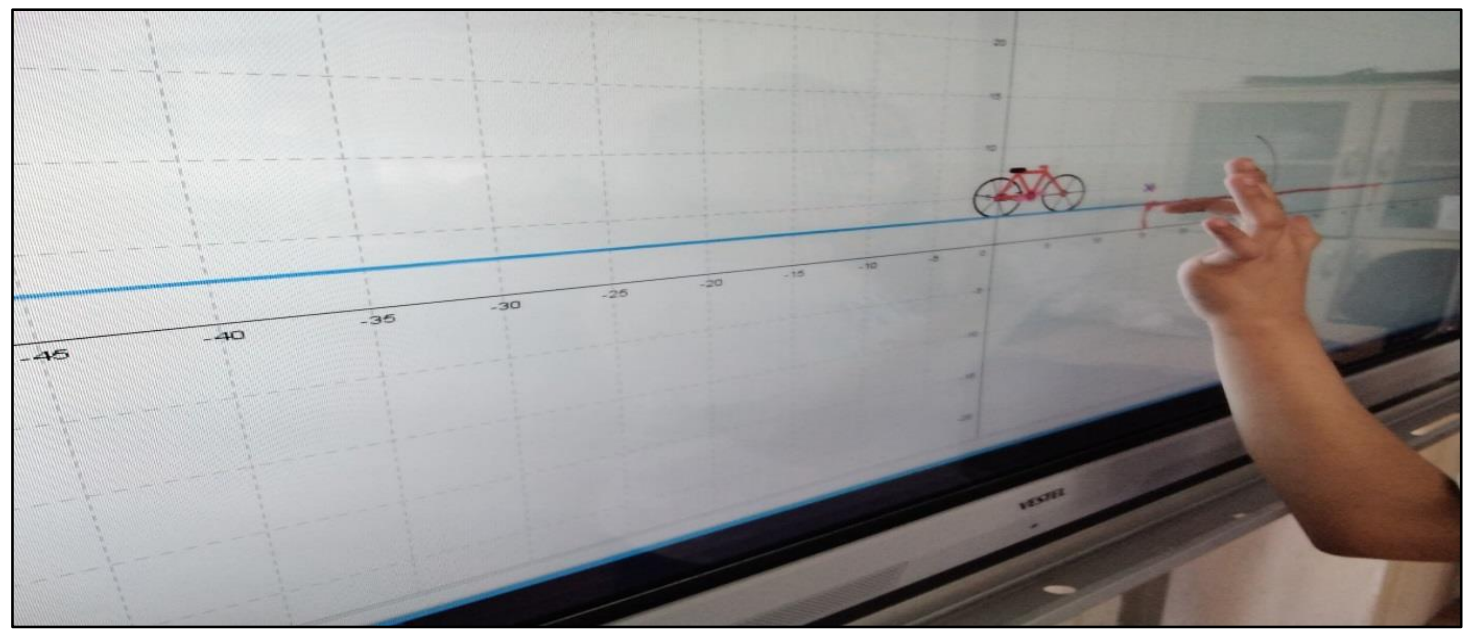

Figure 9: S2's solution on the Geogebra screen

\section{Conclusion and Discussion}

In this study, the purpose was first to have the students realize and then eliminate some of the conceptual deficiencies that occur in the teaching of the subject of slope in the distance education process, with the help of Geogebra, a dynamic geometric software. In line with this purpose, when the findings were examined, it was seen that what the students learned about the subject brought different perspectives. The fact that students stay away from interacting with their teachers during the distance education process is actually an obstacle to receiving direct feedback (Kilit \& Güner, 2021). It could be stated that being away from mutual interaction causes deficiencies in learning some concepts, especially the concept of slope. In this respect, urgent distance education may also require urgent feedback. These feedbacks can be provided with the help of dynamic software that students may be curious about. With the help of such software, the student consciously makes every situation that s/he will formulate in order to create a solid ground by being aware of his/her own mental world (Karataş \& Güven, 2003). 
When the findings obtained in the study are interpreted and evaluated, the mistakes made by the students in teaching the concept of slope in general could be briefly summarized as follows:

- "Seeing each element as belonging to a different pair in creating ordered pairs." This result showed similarities with the study conducted by Hatısaru (2009). The students had difficulties in locating the ordered pairs.

- "Getting a separate line with each ordered pair." This lack of knowledge was manifested in the need for more than one point to draw a line. This result was similar to the study carried out by Yemen (2009).

- "Making over-generalize or ignoring the positive or negative sign of the slope when calculating the slope of the line." This shows that the students focused only on finding the result rather than interpreting the slope value (Deniz \& Kabael, 2017).

- "Cases of slope being undefined and being zero." In these cases, the student was able to make sense of it after making inferences like "cannot climb the wall", which she found by solving it while getting confused initially.

While the students had difficulty in making comments and making inferences by looking at the drawings they made, they were able to make realistic inferences when they saw the activity. At the same time, they were able to advance the process in a positive way by transforming the situations they saw in real life into similar problems. This shows us that the students crossed the threshold in the course of their mathematical abilities and were able to imagine and visualize (Güven \& Karataş, 2003).

Although the one-on-one contact with the teacher has decreased in the emergency distance education process, which requires the student to keep himself/herself at home in daily life, his/her relationship with daily life has increased a little more. This made it easier for the student to make sense of unreal situations by reducing them to real and then to make high-level comments. We were able to observe this situation in the students' response to the negative slope. In order to increase this and similar expressions, classroom environments should be created where students can freely express their ideas (Başarmak \& Mahiroğlu, 2015).

In addition, when the findings were examined, it was observed that a large part of the predicted concept learning deficiencies in the students decreased with the use of the activity called Bicycle-Slope, which was developed by Kavak (2013).

\section{Suggestions}

In this respect, the suggestions to be put forward could be to construct classroom environments with the idea that students will express themselves better in an environment open to classroom discussions, to move daily life situations into the classroom rather than to keep them away from the classroom, and to have students realize that mathematics subjects are in life and in its essence. Moreover, dynamic software, augmented reality and the steps like carrying the technological developments 
to the classroom environment and realizing the teaching will also contribute to the mathematical development of the students.

\title{
Conflict of Interest Statement
}

The authors declare no conflicts of interests.

\begin{abstract}
About the Authors
Elif Ertem-Akbaş works as an assistant professor in the Faculty of Education at Yuzuncu Yil University, Turkey. She completed her doctoral study in mathematics education. She works on the integration of technology into education.
\end{abstract}

Kübra Alan is a mathematics teacher in Turkey and a graduate student at Van Yuzuncu Y1l University, Turkey.

\section{References}

Aktümen M, Horzum T, Yıldız A, Ceylan T, (2010). A dynamic math software: GeoGebra and elementary school $6^{\text {th }}-8^{\text {th }}$ grade sample activities for math lessons. http://w3.gazi.edu.tr/web/aktumen/dosyalar/geo gebraturkiye.pdf

Bakker A, Wagner D, (2020). Pandemic: Lessons for Today and Tomorrow. Educational Studies in Mathematics, 104: 1-4. doi: 10.1007/s10649-020-09946-3

Başarmak U, Mahiroğlu A, (2015). Student Opinions about Cartoon Animation Used in Online Learning Environment. International Journal of Eurasia Social Science. International Journal of Eurasia Social Science, 6(19): 234-253.

Bozkurt A, (2020). The Coronavirus (Covid-19) Pandemic Process and Evaluations on Education in the Post-Pandemic World: New Normal and New Education Paradigm. Journal of open education practices and research. Journal of open education practices and research, 6(3). doi: $\underline{10.21449 / i j a t e .875293}$

Bozkurt A, Sharma C, (2020). Emergency Remote Teaching in a time of Global Crisis due to CoronaVirus Pandemic. Asian Journal of Distance Education, 15(1). doi: $\underline{10.5281 / \text { zenodo.3778083 }}$

Creswell W, (2020). Qualitative research methods: Qualitative research and research design according to five approaches. Ankara: Siyasal Bookstore.

Deniz Ö, Kabael T, (2017). The Processes of Forming the Concept of Slope for $8^{\text {th }}$ Grade Students. Journal of Education and Science, 42(192): 139-172. doi: 10.15390/EB.2017.6996

Er S, Sağlam Kaya Y, (2017). Opinions of Secondary School Mathematics Preservice Teachers about Material Development in Geogebra Environment. Journal of Education Faculty, Mersin University, 13 (1): 228-242. doi: 10.17860/mersinefd.305950 
Gül B, (2014). An Investigation of the Relationship between the Mathematical Achievement of the $8^{\text {th }}$ Grade Students in the Subject of Triangles and the Levels of Van Hiele Geometric Thinking. Master's thesis, Gazi University.

Güven B, Karataş İ, (2003). Learning Geometry with the Dynamic Geometry Software Cabri: Student Opinions. The Turkish Online Journal of Educational Technology, 2(2): 67-78.

Hatısaru V, (2009, November). How Should Mathematics Education Be? Sample Application with Grade-Repeating Students. $8^{\text {th }}$ Mathematics Symposium, Ankara.

Hohenwarter M, Hohenwarter J, (2011). Geogebra Official User Manual (translated by M. Doğan and E. Karakırık) Ankara: Nobel. (Original work published 2008).

Hohenwarter M, Preiner J, (2007). Dynamic Mathematics with GeoGebra. The Journal of Online Mathematics and its Applications, Volume 7. Article ID 1448.

Kavak H, (2013). https://www.geogebra.org/material/show/id/BQnDeXtw. Access date: 17.04.2021.

Kilit B, Güner, P, (2021). Opinions of Mathematics Teachers about Web-Based Distance Education in Mathematics Lessons. Journal of Social Sciences Anemon Muş Alparslan University, 9 (1): 85-102. doi: 10.18506/anemon.803167

Krefting L, (1991). Rigor in qualitative research: the assessment of trustworthiness. The American Journal of Occupational Therapy, 45 (3): 214-222. doi: $10.5014 /$ ajot.45.3.214

Kutluca T, Zengin Y, (2011). Evaluation of Student Views about the Use of Geogebra in Mathematics Teaching. Journal of Dicle University Ziya Gökalp Faculty of Education, (17): 160-172.

MNE (2018). Mathematics Curriculum in Primary and Secondary Schools, Ankara.

MNE (2020). Mathematics Curriculum in Vocational Education Centers, Ankara.

Sarıtaş E, Barutçu S, (2020). Digital Transformation in Education and Students' Readiness for Online Learning: A Study on Pamukkale University Students during the Pandemic Period. Journal of İnternet Applications and Management, 11 (1): 5-22. doi: 10.34231/iuyd.706397

Sezgin S, (2021). Analysis of the Emergency Distance Education Process: Featured Concepts, Problems and Lessons Learned. Anadolu University Journal of Social Sciences, 21 (1): 273-296. doi: 10.18037/ausbd.902616

Telli S, Altun D, (2020). The Coronavirus and the Unstoppable Rise of Online Education. Journal of University Studies, 3 (1): 25-34. doi: 10.32329/uad.711110

Tomic W, Nelissen J, Representations in Mathematics Education, Hearken. ERIC Document Reproduction Service No. ED 428950, (1998).

Topraklıkoğlu K, (2018). Teaching Geometry with Augmented Reality Activities Using Three-Dimensional Modeling. Master's thesis, Balikesir University.

Uzun K, (2018). The Effect of Teaching Linear Equations and Slope with Dynamic Geometry Software Geogebra on $8^{\text {th }}$ Grade Students' Conceptual Understanding and Permanence. Master's thesis. Uşak University. 
Üzel D, (2007). The Effect of Education Supported with Realistic Mathematics Education (RME) on Student Achievement in Elementary $7^{\text {th }}$ Grade Mathematics Teaching. Doctoral thesis, Balikesir University.

Yemen S, (2009). The Effect of Technology-Supported Education on Students' Achievement and Attitudes in Teaching Analytical Geometry at Elementary School $8^{\text {th }}$ Grade. Master's thesis, Dokuz Eylul University.

Yenilmez K, Kocaoğlu T, (2010). $5^{\text {th }}$ Grade Students' Errors and Misconceptions in Fraction Problems. Journal of Dicle University Ziya Gökalp Faculty of Education, (14): 71-85.

Yıldırım A, Şimşek H, Qualitative Research Methods in Social Sciences, Ankara: Seçkin Publication, 2018. 
Elif Ertem Akbaş, Kübra Alan

EVALUATION OF CONCEPT LEARNING DEFICIENCIES ENCOUNTERED

IN TEACHING SLOPE IN THE EMERGENCY DISTANCE EDUCATION PROCESS

Creative Commons licensing terms

Author(s) will retain the copyright of their published articles agreeing that a Creative Commons Attribution 4.0 International License (CC BY 4.0) terms will be applied to their work. Under the terms of this license, no permission is required from the author(s) or publisher for members of the community to copy, distribute, transmit or adapt the article content, providing a proper, prominent and unambiguous attribution to the authors in a manner that makes clear that the materials are being reused under permission of a Creative Commons License. Views, opinions and conclusions expressed in this research article are views, opinions and conclusions of the author(s). Open Access Publishing Group and European Journal of Education Studies shall not be responsible or answerable for any loss, damage or liability caused in relation to/arising out of conflicts of interest, copyright violations and inappropriate or inaccurate use of any kind content related or integrated into the research work. All the published works are meeting the Open Access Publishing requirements and can be freely accessed, shared, modified, distributed and used in educational, commercial and non-commercial purposes under a Creative Commons Attribution 4.0 International License (CC BY 4.0). 